\title{
Chromium(III) biosorption onto spent grains residual from brewing industry: equilibrium, kinetics and column studies
}

\author{
A. I. Ferraz • C. Amorim • \\ T. Tavares $\cdot$ J. A. Teixeira
}

Received: 29 April 2013/Revised: 10 December 2013/ Accepted: 5 March 2014/Published online: 19 March 2014

(C) Islamic Azad University (IAU) 2014

\begin{abstract}
The use of industrial wastes for wastewater treatment as a strategy to their re-use and valorisation may provide important advances toward sustainability. The present work gives new insights into heavy metal biosorption onto low-cost biosorbents, studying chromium(III) biosorption onto spent grains residual from a Portuguese brewing industry both in batch and expanded bed column systems. Experimental studies involved unmodified spent grains and spent grains treated with $\mathrm{NaOH}$. Metal uptake followed a rapid initial step, well described by the pseudosecond-order kinetic model up to $2-7 \mathrm{~h}$, indicating chemisorption to be the rate-limiting step. Beyond this period intraparticle diffusion assumed an important role in the uptake global kinetics. The best fit for equilibrium data was obtained using the Langmuir model, with unmodified spent grains having the higher maximum uptake capacity $\left(q_{\max }=16.7 \mathrm{mg} \mathrm{g}^{-1}\right)$. In open system studies, using expanded bed columns, the best performance was also achieved with unmodified spent grains: Breakthrough time $\left(C / C_{\mathrm{i}}=0.25\right)$ and total saturation time $\left(C / C_{\mathrm{i}}=0.99\right)$ occurred after 58 and $199 \mathrm{~h}$ of operation, corresponding to the accumulation of $390 \mathrm{mg}$ of chromium(III), $43.3 \%$ of the total amount entering the column. These results suggest that alkali treatment does not improve spent grains uptake performance. Changes in biomass composition determined by Fourier transform infrared spectroscopy suggested
\end{abstract}

A. I. Ferraz · C. Amorim - T. Tavares · J. A. Teixeira CEB - Centre of Biological Engineering, University of Minho, Campus de Gualtar, 4710-057 Braga, Portugal

\section{A. I. Ferraz ( $\square)$}

Instituto Politécnico de Viana do Castelo, Escola Superior Agrária, 4990-706 Ponte de Lima, Portugal

e-mail: aferraz@esa.ipvc.pt hydroxyl groups and proteins to have an important role in chromium(III) biosorption. This study points out that unmodified spent grains can be successfully used as lowcost biosorbent for trivalent chromium.

Keywords Breakthrough curves - Heavy metals . Low-cost biosorbents · Waste valorisation

\section{Introduction}

Heavy metals are considered major inorganic pollutants as a result of their recalcitrance and persistence in the environment, high mobility in aquatic systems, high toxicity and the accumulation through the food chain. Thus, it is unanimously considered that their uncontrolled discharge into natural water streams poses serious environmental and public health risks. Simultaneously, environmental management guidelines and regulations concerning metal discharges and waste disposal are becoming progressively stricter, pointing to strategies that include wastewater and residues minimization, recycling and valorisation.

Wastewater from industrial activities such as electroplating, metal finishing, tanneries, textile dyeing and cooling water systems may contain chromium concentrations up to several hundreds of $\mathrm{mg} \mathrm{L}^{-1}$. Chromium(III) and chromium(VI) are the species with major environmental impacts because of their stability and widespread in aquatic environments. Chromium physiologic and ecotoxicological effects depend upon its oxidation state and concentration. Therefore, although chromium(VI) has higher toxicity, high concentrations of chromium(III) have toxic and mutagenic effects resulting in plant growth inhibition and immune system activity reduction, and may cause allergies and cancer (Donmez and Kocberber 2005; Gardea- 
Torresdey et al. 2005). According to Sawalha et al. (2007) chromium(III) can form potentially toxic, carcinogenic or mutagenic compounds even at low concentrations. Furthermore, when released into ecosystems, trivalent and hexavalent forms may undergo oxidation-reduction reactions that convert chromium species one into the other being impossible to guarantee safety inherent to the most innocuous one.

These issues give emphasis to the need of developing new technologies, more efficient and economical, to treat wastewater contaminated with heavy metals. In that regard, biosorption can be assumed as a promising technology to treat high volumes of dilute solutions, where the use of residual biomass from industrial or agronomic activities enhances the possibility of these endogenous products' valorisation in environmental biotechnology applications.

At the present, economic and environmental considerations are leading to the use of new low-cost adsorbents derived from renewable resources. Lignocellulosic wastes have been widely studied for metal removal from water and are considered to be comparable to sorbents from other natural sources, with advantages resulting from their availability, low-cost and simple operational process (Miretzky and Cirelli 2010). Among them, it is possible to refer the use of agriculture wastes such as rice milling by-products (Tarley and Arruda 2004), rice bran (Fatima et al. 2013), carrot residues (Nasernejad et al. 2005), orange waste (Marín et al. 2009, 2010), coconut husk (Acheampong et al. 2011), grape bagasse (Farinella et al. 2007), and sorghum straw, oats straw and agave bagasse (Bernardo et al. 2009).

Brewery spent grains (BSG) are the by-products of mashing process, representing nearly $85 \%$ of total byproducts of brewing industry. Despite its potential as a valuable resource for industrial exploitation, spent grains, rich in cellulose and non-cellulosic polysaccharides, are frequently used as animal feed (Aliyu and Bala 2011; Li et al. 2009a). Nevertheless, because of BSG chemical composition, particularly its considerable amount of dietary fibers, other applications have been explored: as an additive for dietary food, the production of fermentable sugars and soluble non-digestible oligomers that may act as prebiotics (Macheiner et al. 2003), as immobilization support for microorganisms, namely brewing yeast and bacteria (Branyik et al. 2004) and also as a biosorbent for heavy metals (Low et al. 2000, 2001; Ferraz et al. 2005; Li et al. 2009a; Lu and Gibb 2008).

BSG chemical composition may differ according to the barley characteristics, brewery's conditions and the ingredients used (Carvalheiro et al. 2004). These authors present an average composition for BSG (dry weigh basis) of glucan $(21.9 \%)$, xylan (20.6\%), arabinan $(9.0 \%)$, Klason lignin $(21.7 \%)$, acetyl groups $(1.1 \%)$, protein $(24.6 \%)$ and ashes $(1.2 \%)$.
The main goals of biosorption studies are the characterization of mechanisms involved and the way they are affected by the environmental conditions, in order to successfully develop large-scale systems. The first step toward these objectives is the quantification of biosorbent uptake capacity, traditionally by the characterization of the equilibrium state reached when it is placed in contact with an aqueous solution of the metal of interest (Davis et al. 2003).

The present study, carried out in the Center of Biological Engineering from 2005 to 2010, gives contributions to evaluate spent grains residual from a Portuguese brewing industry (UNICER) valorization potential, as low-cost and biodegradable biosorbents regarding the decontamination of $\mathrm{Cr}$ (III) solutions. With this purpose, $\mathrm{Cr}$ (III) biosorption onto unmodified spent grains and spent grains treated with $\mathrm{NaOH}$ equilibrium and kinetics was characterized. Therefore, investigation was conducted in order to determine the kinetic model that best describes the biosorption system behavior, also indicating the nature of the mechanism involved (diffusion or chemisorption), followed by the quantification of $\mathrm{Cr}$ (III) sorption capacity and affinity to the biosorbents by fitting the equilibrium models to the experimental data. Spent grains Fourier transform infrared spectroscopy (FTIR) data provided information to identify the effect of alkaline treatment on spent grains and to better understand $\mathrm{Cr}(\mathrm{III})$ uptake mechanism. Furthermore, both biosorbents were used to assess wastewater treatment in continuous systems, using expanded bed columns to determine breakthrough curves.

\section{Materials and methods}

\section{Biosorbent preparation}

Fresh spent grains were successively washed with distilled water, then dried at $60{ }^{\circ} \mathrm{C}$ and finally screened through a $1-\mathrm{mm}$ sieve. The material obtained is considered to be unmodified and will be designated as NTSG (Not Treated Spent Grains). Afterward, part of this material was treated with a sodium hydroxide solution $0.5 \mathrm{M}$ for $4 \mathrm{~h}$ at room temperature. The excess of alkaline solution was removed by washing spent grains with distilled water until constant supernatant $\mathrm{pH}$ was reached in successive washings, according to the procedure described by Low et al. (2000). This material will be designated as TSG (Treated Spent Grains).

Metal solutions

Metal solutions were prepared dissolving $\mathrm{CrCl}_{3} \cdot 6 \mathrm{H}_{2} \mathrm{O}$ in distilled water. Metal solutions $\mathrm{pH}$ was adjusted to 5.0 with $\mathrm{NaOH} 0.1 \mathrm{M}$. 
Batch assays

Biosorption kinetics and equilibrium assays were carried out in Erlenmeyer flasks using $\mathrm{Cr}$ (III) solutions with initial concentrations ranging from 10 to $400 \mathrm{mg} \mathrm{L}^{-1}$. Biosorbents were added in order to reach a biomass concentration of $5 \mathrm{~g} \mathrm{~L}^{-1}$, and the flasks were incubated at $30^{\circ} \mathrm{C}$ with orbital shaking $(150 \mathrm{rpm})$. The high agitation speed ensures that external diffusion can be neglected. Batch systems were monitored until stationary state was reached.

\section{Biosorption kinetics}

Sorption kinetics describes the solute uptake rate, expressing the residence time necessary to achieve the expected metal removal performance within a sorption system. Kinetic studies give important contributions concerning the time required to reach equilibrium, to develop predictive models for column experiments, to better understand the variables influencing the process and to design appropriate sorption treatment plants, and the biosorption mechanism involved.

The processes controlling sorption kinetics may include (1) bulk diffusion; (2) external mass transfer; (3) chemical reaction (chemisorption); and (4) intraparticle diffusion. Any of these processes, individually or in combination, may be the rate-controlling step. Compared with traditional technologies, the intrinsic kinetics of biosorption is usually fast, and equilibrium is achieved within a few minutes, leading to operational advantages such as the use of low volume reactors with high efficiency and low-energy consumption. When high agitation speeds are used, the bulk diffusion step can be ignored, and when the chemisorption at the solid phase is rapid and is not associated with solidphase transport processes, the liquid-phase transport process determines the overall rate of reaction, e.g., the diffusion across the liquid film surrounding the solid particles or the diffusion in liquid-filled macropores (Ho et al. 2000).

Several kinetic models with varying degrees of complexity have been developed to describe metal biosorption kinetics in batch systems.

\section{Sorption reaction models: Lagergren equation rate and Pseudo-second-order model}

Lagergren pseudo-first-order model, expressed by Eq. 1, assumes that the interaction rate is limited by only one process or mechanism on a single class of sorbing sites and that all sites are time dependent (Fonseca et al. 2009). The Lagergren rate equation not always fits well data for the whole contact time range, being only applicable during the initial 20-30 min of the biosorption process (Aksu 2001). $\frac{\mathrm{d} q_{\mathrm{t}}}{\mathrm{d} t}=k_{1}\left(q_{\mathrm{e}}-q_{\mathrm{t}}\right)$

where $q_{\mathrm{e}}$ and $q_{\mathrm{t}}\left(\mathrm{mg} \mathrm{g}^{-1}\right)$, respectively, represent the amount of metal sorbed at equilibrium and any time $t$; and $k_{1}\left(\mathrm{~min}^{-1}\right)$ is the rate constant of first-order sorption.

The pseudo-second-order equation rate assumes chemisorption as the rate-limiting step, with complexation and ion exchange being the main mechanisms involved, depending on the solid-phase sorption capacity. Therefore, pseudo-second-order equation rate depends on the sorption equilibrium capacity but not on the sorbate concentration, assuming the linearized form expressed in Eq. 2 (Aksu 2001; Ozer et al. 2004):

$\frac{t}{q_{\mathrm{t}}}=\frac{1}{k_{2} q_{\mathrm{e}}^{2}}+\frac{1}{q_{\mathrm{e}}} t$

where $k_{2}\left(\mathrm{~g} \mathrm{mg}^{-1} \mathrm{~min}^{-1}\right)$ is the equilibrium rate constant of pseudo-second-order sorption. Using this expression, it is possible to calculate the equilibrium sorption capacity, the pseudo-second-order rate constant and the initial sorption rate, $h=\sqrt{k_{2} q_{\mathrm{e}}^{2}}$, (Ho and Mckay 2004).

\section{Sorption diffusion model: intraparticle diffusion}

Weber and Morris (1962) developed a simple sorption diffusion model that considers the change of the fractional approach to equilibrium according to a function of $\left(D t / r^{2}\right)^{1 / 2}$, where $r$ is the particle radius and $D$ is the solute diffusivity within the particle (Eq. 3). If this phenomenon is the biosorption rate-controlling step limiting sorption velocity, the plot $q_{\mathrm{t}}$ versus $t^{1 / 2}$ will result in a straight line passing through the origin, and the intraparticle diffusion coefficient, $k_{\mathrm{d}}\left(\mathrm{mg} \mathrm{g}^{-1} \min ^{-1 / 2}\right)$, can be determined by the line slope (Ho et al. 2000):

$q_{\mathrm{t}}=k_{\mathrm{d}} t^{1 / 2}$

The plot $q_{\mathrm{t}}$ versus $t^{1 / 2}$ may present multi-linearity, indicating multiple sorption mechanisms (Marín et al. 2010). The first portion, with higher slope, usually corresponds to the external surface biosorption stage, the second to the gradual biosorption stage, where intraparticle diffusion is rate controlling, and finally, the third stage corresponds to the equilibrium where the intraparticle diffusion starts to slow down as a result of low solute concentration in the solution. The following is the order for the magnitude of the diffusion coefficients for these three stages: $k_{\mathrm{d} 1}>k_{\mathrm{d} 2}>k_{\mathrm{d} 3}$ (Gulnaz et al. 2005).

\section{Biosorption equilibrium}

Equilibrium models are generally classified as mechanistic models, when they are based on the biosorption 
mechanism, or as empirical models. Although the mechanistic models developed, the ion exchange and the surface complexation models can be used to represent, explain and also to predict the system experimental behavior (Wang and Chen 2006); in this study, only the more commonly used empirical models, the Langmuir and the Freundlich model, will be considered. These models, being useful to quantitatively evaluate metal sorption onto different biosorbents and to estimate maximum uptake capacity, cannot provide any mechanistic understanding of the sorption phenomena and cannot be used to predict the effect of environmental variables such as medium $\mathrm{pH}$ or ionic strength. Their utilization rests on the adequacy between the experimentally observed tendencies and the shape of the mathematical laws associated (Benguella and Benaissa 2002; Wang and Chen 2006).

Sorption equilibrium is reached when the metal concentration in the bulk solution is in dynamic balance with that of the interface (Ho et al. 2000). The metal uptake (q) is determined from the system mass balance considering that all the metal missing in the bulk solution is bound to the solid phase:

$q=\frac{\left(C_{\mathrm{i}}-C\right) V}{X}$

where $C_{\mathrm{i}}\left(\mathrm{mg} \mathrm{L}^{-1}\right)$ is the initial metal concentration, $C\left(\mathrm{mg} \mathrm{L}^{-1}\right)$ is the metal concentration at incubation time $t$, $V$ is the metal solution volume $(L)$ and $X(\mathrm{~g})$ is the biosorbent dry weigh.

\section{Langmuir model}

Langmuir equilibrium model, originally developed to describe the gas-solid adsorption equilibrium onto activated carbon, has been largely used to quantify and compare the performance of different sorbents (Davis et al. 2003). This model considers sorption as a chemical phenomenon (Volesky 2003) and has been successfully applied to several pollutants sorption processes assuming the form:

$q_{\mathrm{e}}=q_{\max }\left(\frac{b C_{\mathrm{f}}}{1+b C_{\mathrm{f}}}\right)$

where $q_{\mathrm{e}}\left(\mathrm{mg} \mathrm{g}^{-1}\right)$ is the metal uptake at equilibrium, $q_{\max }$ $\left(\mathrm{mg} \mathrm{g}^{-1}\right)$ is the maximum uptake capacity, representing the practical limit for the sorption capacity, $C_{\mathrm{f}}\left(\mathrm{mg} \mathrm{L}^{-1}\right)$ is the final metal concentration in solution at equilibrium and $b$ is a constant related to the affinity between the sorbent and the metal (Davis et al. 2003). Thus, although this empirical model cannot be used to conclude about the biosorption mechanisms involved, the two parameters considered, $q_{\max }$ and $b$, are easily interpretable, being useful to quantitatively assess biosorption performance and directly compare different biosorbents (Loukidou et al. 2004a).

\section{Freundlich model}

Similarly to the Langmuir isotherm equation, the Freundlich model has been largely used to quantify equilibrium biosorption systems, describing the extent of sorption as a function of metal equilibrium concentration in solution:

$q_{\mathrm{e}}=K_{\mathrm{F}} C_{\mathrm{f}}^{1 / N}$

where $K_{\mathrm{F}}$ and $N$ are empirical constants that can be determined by the linear plot of $\ln \left(q_{\mathrm{e}}\right)$ versus $\ln \left(C_{\mathrm{f}}\right)$, respectively, related to the maximum binding capacity and the binding affinity or binding strength. Adsorption is favorable when $N>1$ (Ozer et al. 2004). According to Volesky (2003), this model does not indicate a finite uptake capacity of the sorbent and can only be reasonably applied in the low-to-intermediate concentration ranges.

\section{Column biosorption experiments}

To design and operate biosorption in continuous systems, it is convenient to have information concerning its maximum uptake capacity and to predict breakthrough curves profiles.

Column biosorption assays were performed in a perspex column (internal diameter $=3.2 \mathrm{~cm}$; height $=39 \mathrm{~cm}$ ), with temperature control $\left(30^{\circ} \mathrm{C}\right)$. Metal solution with $C_{\mathrm{i}}=50 \mathrm{mg} \mathrm{Cr}(\mathrm{III}) \mathrm{L}^{-1}$ was fed in up-flow with a $1.5 \pm 0.1 \mathrm{~mL} \mathrm{~min}^{-1}$ flow rate. Experimental chromium breakthrough curves were obtained using expanded bed columns filled with NTSG (25 g) and TSG (20 g). Biomass fluidization conditions, similar in all assays, were ensured using high recirculation rates, nearly 107 . The difference in spent grains mass used in experimental assays results from materials different densities, with consequences in fluidization characteristics. The lower density of TSG is explained by intercrystalline swelling of cellulose by breaking down hydrogen bonding of adjacent glucose molecule in cellulose matrix caused by alkaline pre-treatment (Macheiner et al. 2003).

With the high recirculation rate used to fluidize spent grains, column hydrodynamic conditions can be assumed to be similar to a continuous stirred tank reactor (CSTR). Therefore, biosorption system performance was assessed comparing experimental breakthrough curves with predictions using a model resulting from the application of Langmuir equation to a continuous stirred tank reactor mass balance, also used by Veglio et al. (2000) and Reddad et al. (2003) to simulate $\mathrm{Cu}(\mathrm{II})$ biosorption in membrane reactors. System mass balance is given by Eq. 7: 
$V_{\mathrm{r}} \frac{\mathrm{d} C_{\mathrm{e}}}{\mathrm{d} t}=F C_{\mathrm{i}}-F C_{\mathrm{e}}-\frac{\mathrm{d} q}{\mathrm{~d} t} X$

where $V_{\mathrm{r}}(L)$ corresponds to the reactor volume, $C_{\mathrm{e}}$ $\left(\mathrm{mg} \mathrm{L}^{-1}\right)$ is the metal concentration in the outlet flow, $F$ is the feed flow rate $\left(0.09 \mathrm{~L} \mathrm{~h}^{-1}\right), q$ is $\mathrm{Cr}$ (III) uptake and $X\left(\mathrm{~g} \mathrm{~L}^{-1}\right)$ is the biomass concentration.

Assuming that biosorption is a rapid phenomenon, the column can be considered in equilibrium (Veglio et al. 2000). Hence, replacing Langmuir model in Eq. 7, it is obtained, where $K=1 / b$ :

$\frac{\mathrm{d} C_{\mathrm{e}}}{\mathrm{d} t}=\frac{F\left(C_{\mathrm{i}}-C_{\mathrm{e}}\right)}{V\left(1+\frac{q_{\max } K X}{\left(C_{\mathrm{e}}+K\right)^{2}}\right)}$

Analytical methods

\section{Determination of chromium concentration}

Chromium concentration was determined by atomic absorption spectroscopy after biomass removal from solution by filtration. Samples were preserved by acidification $(\mathrm{pH}<2)$ with concentrated $\mathrm{HNO}_{3}$ and kept at $4{ }^{\circ} \mathrm{C}$.

\section{Fourier transform infrared spectroscopy}

Fourier transform infrared spectroscopy analyses were conducted to qualitatively assess the effect of alkaline treatment in spent grains chemical composition and to identify the main functional groups involved in $\mathrm{Cr}(\mathrm{III})$ biosorption. Samples from NTSG to TSG collected after different contact times with $\mathrm{Cr}$ (III) solutions were dried at $60{ }^{\circ} \mathrm{C}$ and grounded to form a homogeneous mass. Disks with $150 \mathrm{mg}$ of $\mathrm{KBr}$ containing $1 \%$ of the powdered biomass were prepared submitting the mixture to vacuum followed by 200 bar pressure for $5 \mathrm{~min}$. Controls were prepared using spent grains without contact with chromium. Spectra were obtained in FTIR spectrophotometer (BOMEN MB Serie) within the range of $500-4000 \mathrm{~cm}^{-1}$.

\section{Results and discussion}

$\mathrm{Cr}(\mathrm{III})$ sorption kinetics onto brewery spent grains

Metal accumulation profile onto NTSG and TSG presented in Fig. 1 shows that, as expectable, $\mathrm{Cr}$ (III) uptake increases with increasing $C_{\mathrm{i}}$ when biomass concentration is kept constant. Initial metal concentration provides an important driving force to overcome the metal mass transference resistances between the aqueous and the solid phase, contributing to enhance biosorption (Gulnaz et al. 2005; Barka et al. 2010).
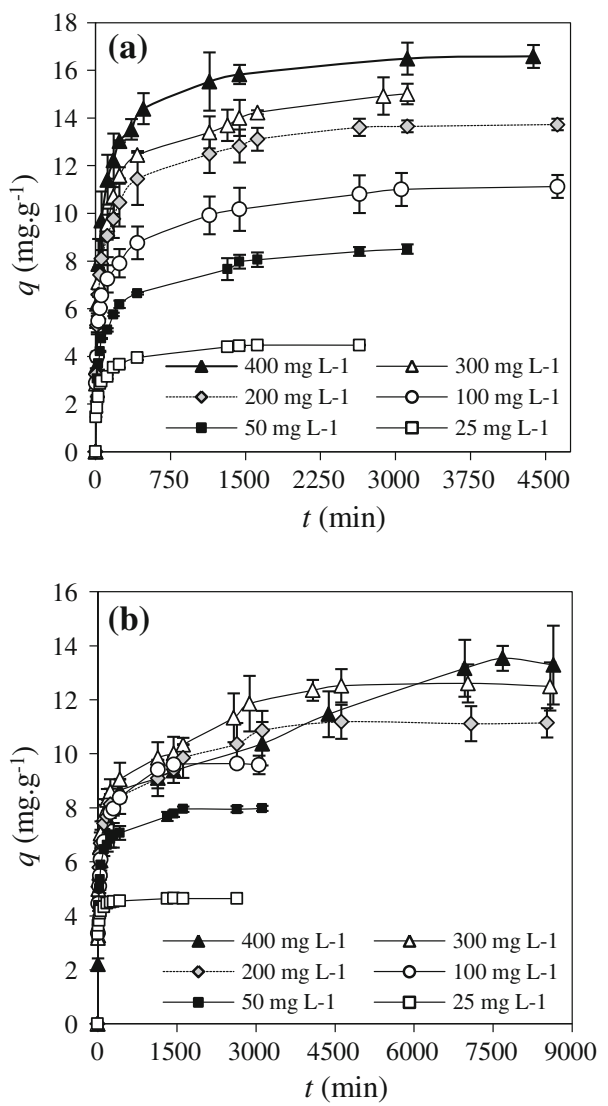

Fig. $1 \mathrm{Cr}(\mathrm{III})$ accumulation profile onto brewery spent grains: a NTSG; b TSG

Data from Fig. 1 are also consistent with the typical biosorption behavior, with an initial rapid uptake followed by a slower stage probably associated to the metal diffusional limitation through the biosorbent. Initial fast kinetics is typical of biosorption processes involving no energymediated reactions, and metal removal from solution is due to physico-chemical interactions (Quintelas et al. 2009). For NTSG, equilibrium was reached after $27 \mathrm{~h}$ in solution with $C_{\mathrm{i}}=25 \mathrm{mg} \mathrm{L}^{-1}$, and after $52 \mathrm{~h}$ for all the other initial concentrations. Using TSG as biosorbent, equilibrium was attained after $24 \mathrm{~h}$ for $C_{\mathrm{i}}=25,50$ and $100 \mathrm{mg} \mathrm{L}^{-1}$, $77 \mathrm{~h}$ for $C_{\mathrm{i}}=200$ and $300 \mathrm{mg} \mathrm{L}^{-1}$, and only after $128 \mathrm{~h}$ for the solution with $C_{\mathrm{i}}=400 \mathrm{mg} \mathrm{L}^{-1}$.

Considering the different processes that may control sorption kinetics, it is common that more than one simultaneously contributes to the overall uptake rate (Loukidou et al. 2004b). Criteria to choose among the kinetic models available should include fitting to experimental data and the sorption mechanisms taking place (Loukidou et al. 2004a). The simplified approach to avoid this issue suggested by the authors and used in the present paper consists in the assumption that each one of the co-current processes dominates over the others at specific periods, acting as the 

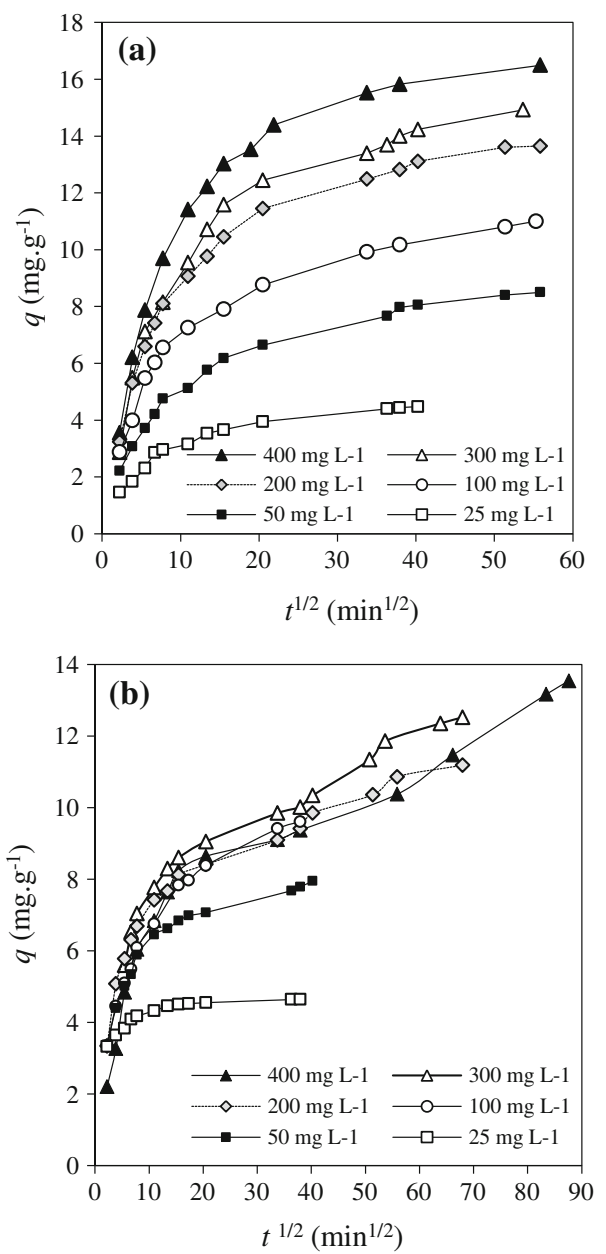

Fig. 2 Intraparticle diffusion sorption kinetics of $\mathrm{Cr}$ (III) onto spent grains at various initial metal concentrations: a NTSG; b TSG

rate-controlling step, and in the independent study of each of them.

Intraparticle diffusion is the rate-controlling step observed in several biosorption systems. That is the case of $\mathrm{Cu}$ (II) sorption onto $S$. cerevisiae (Ho et al. 2000), and the sorption of $\mathrm{Cr}(\mathrm{VI})$ onto Aeromonas caviae (Loukidou et al. 2004b). Being expected this phenomenon to have an important role in the overall $\mathrm{Cr}$ (III) uptake rate due to the long periods necessary to reach equilibrium in most of the sorption systems in study, the first kinetic model to be studied was the intraparticle diffusion rate equation.

Plots in Fig. 2 exhibit two distinct trends: (1) an initially sharp slope, indicating a high metal accumulation rate and (2) a second one with a smaller slope. The same trend was observed with $\mathrm{Cr}(\mathrm{VI})$ and $\mathrm{Cr}(\mathrm{III})$ onto Leersia hexandra Swartz biomass (Li et al. 2009b) and was explained by the existence of more than one diffusional mechanism affecting the process, where the initial part of the curve corresponds to the film diffusion, and the subsequent linear section to the intraparticle diffusion. Hence, intraparticle
Table 1 Spent grains intraparticle diffusion coefficients

\begin{tabular}{|c|c|c|c|c|}
\hline \multirow{2}{*}{$\begin{array}{l}C_{\mathrm{i}} \\
\left(\mathrm{mg} \mathrm{L}^{-1}\right)\end{array}$} & \multicolumn{2}{|l|}{ NTSG } & \multicolumn{2}{|l|}{ TSG } \\
\hline & $\begin{array}{l}k_{\mathrm{d}}\left(\mathrm{mg} \mathrm{g}^{-1}\right. \\
\left.\mathrm{min}^{-1 / 2}\right)\end{array}$ & $r^{2}$ & $\begin{array}{l}k_{\mathrm{d}}\left(\mathrm{mg} \mathrm{g}^{-1}\right. \\
\left.\min ^{-1 / 2}\right)\end{array}$ & $r^{2}$ \\
\hline 400 & 0.0857 & 0.8930 & 0.0832 & 0.9862 \\
\hline 300 & 0.0730 & 0.9719 & 0.0781 & 0.9842 \\
\hline 200 & 0.0634 & 0.9559 & 0.0621 & 0.9806 \\
\hline 100 & 0.0816 & 0.9430 & 0.0804 & 0.9905 \\
\hline 50 & 0.0643 & 0.9918 & 0.0415 & 0.9925 \\
\hline 25 & 0.0342 & 0.9733 & 0.00672 & 0.9576 \\
\hline
\end{tabular}

diffusion coefficients, $k_{\mathrm{d}}$, (Table 1) were determined by the slope of the final linear portion of the curves shown in Fig. 2.

As expected, intraparticle rate parameters for both biosorbents increased with increasing initial metal concentration. For $C_{\mathrm{i}}$ higher than $100 \mathrm{mg} \mathrm{L}^{-1}$, considering the proximity of the calculated $k_{\mathrm{d}}$ values, it may be assumed that intraparticle diffusion plays a similar role in $\mathrm{Cr}(\mathrm{III})$ biosorption onto NTSG and TSG.

According to Miretzky and Cirelli (2010), in most studies reporting $\mathrm{Cr}$ (III) adsorption by different lignocellulosic materials, experimental data followed pseudo-firstorder and pseudo-second-order kinetic models, and the adsorption mechanism identified was electrostatic attraction. Regarding the importance of superficial binding sites in metal biosorption, it is also probable that uptake mechanisms such as chemisorption, including ionic bonding and/or covalent bonding, play a determinant role in the overall sorption rate. Thus, two sorption reaction models, the Lagergren and the pseudo-second-order rate equations, were also fitted to the experimental results.

Models linear fitting to experimental data corresponding to the first linear portion of the curves presented in Fig. 2 lead to higher correlation coefficients and lower deviations (Table 2) compared to the ones obtained when considering data until equilibrium was reached. This behavior reinforces the role of intraparticle diffusion in the overall metal uptake rate for long biosorption contact times, being consistent with $\mathrm{Cr}$ (III) accumulation profile onto brewery spent grains shown in Fig. 1, where it is possible to observe that biosorption systems in study take considerable longer periods to reach equilibrium when compared to similar ones: e.g., $\mathrm{Cd}(\mathrm{II})$ and $\mathrm{Pb}(\mathrm{III})$ biosorption onto brewery spent grains (Low et al. 2000), $\mathrm{Cu}$ (II) onto whisky distilling spent grains (Lu and Gibb 2008) and $\mathrm{Cr}$ (III) biosorption onto eggshells (Chojnacka 2005).

Table 2 reports the kinetic parameters calculated from equation models linear fitting to the experimental results, including their rate constants, respectively, $k_{1}$ and $k_{2}$, the correlation coefficient, $r^{2}$, the equilibrium metal uptake 
Table 2 Comparison of the Lagergren and the pseudo-second-order rate equations constants, calculated and experimental Cr(III) equilibrium uptake, and deviation at different metal concentrations

\begin{tabular}{|c|c|c|c|c|c|c|c|c|c|c|}
\hline \multirow[t]{2}{*}{ Biosorbent } & \multirow{2}{*}{$\begin{array}{l}C_{\mathrm{i}} \\
\left(\mathrm{mg} \mathrm{L}^{-1}\right)\end{array}$} & \multicolumn{3}{|l|}{ Lagergren } & \multicolumn{4}{|c|}{ Pseudo-second order } & \multirow{2}{*}{$\begin{array}{l}q_{\mathrm{e}, \exp } \\
\left(\mathrm{mg} \mathrm{g}^{-1}\right)\end{array}$} & \multirow[t]{2}{*}{$\Delta q(\%)$} \\
\hline & & $K_{1}\left(\min ^{-1}\right)$ & $\begin{array}{l}q_{\mathrm{e}, \mathrm{cal}} \\
\left(\mathrm{mg} \mathrm{g}^{-1}\right)\end{array}$ & $r^{2}$ & $\begin{array}{l}K_{2}\left(\mathrm{~g} \mathrm{mg}^{-1}\right. \\
\left.\min ^{-1}\right)\end{array}$ & $\begin{array}{l}h\left(\mathrm{mg} \mathrm{g}^{-1}\right. \\
\left.\min ^{-1}\right)\end{array}$ & $\begin{array}{l}q_{\mathrm{e}, \mathrm{calc}} \\
\left(\mathrm{mg} \mathrm{g}^{-1}\right)\end{array}$ & $r^{2}$ & & \\
\hline \multirow[t]{6}{*}{ NTSG } & 400 & $5.15 \times 10^{-3}$ & 10.76 & 0.9280 & $3.47 \times 10^{-3}$ & 0.665 & 13.84 & 0.9972 & 16.49 & 10.9 \\
\hline & 300 & $4.79 \times 10^{-3}$ & 10.18 & 0.9416 & $3.55 \times 10^{-3}$ & 0.533 & 12.26 & 0.9932 & 15.01 & 11.0 \\
\hline & 200 & $4.40 \times 10^{-3}$ & 8.43 & 0.9001 & $4.85 \times 10^{-3}$ & 0.584 & 10.97 & 0.9966 & 13.65 & 11.7 \\
\hline & 100 & $1.10 \times 10^{-2}$ & 8.24 & 0.9651 & $1.20 \times 10^{-2}$ & 0.695 & 7.60 & 0.9912 & 11.01 & 10.1 \\
\hline & 50 & $5.15 \times 10^{-3}$ & 5.76 & 0.8507 & $1.53 \times 10^{-2}$ & 0.475 & 5.57 & 0.9954 & 8.50 & 11.9 \\
\hline & 25 & $7.11 \times 10^{-3}$ & 2.71 & 0.8027 & $2.76 \times 10^{-2}$ & 0.325 & 3.43 & 0.9954 & 4.47 & 12.6 \\
\hline \multirow[t]{6}{*}{ TSG } & 400 & $1.93 \times 10^{-3}$ & 9.40 & 0.8049 & $3.97 \times 10^{-3}$ & 0.329 & 9.10 & 0.9974 & 13.54 & 14.4 \\
\hline & 300 & $3.98 \times 10^{-3}$ & 7.93 & 0.8443 & $8.47 \times 10^{-3}$ & 0.653 & 8.78 & 0.9976 & 12.52 & 11.3 \\
\hline & 200 & $3.95 \times 10^{-3}$ & 6.43 & 0.8055 & $1.22 \times 10^{-2}$ & 0.791 & 8.04 & 0.9990 & 11.18 & 9.1 \\
\hline & 100 & $6.40 \times 10^{-3}$ & 5.72 & 0.9101 & $1.40 \times 10^{-2}$ & 0.723 & 7.18 & 0.9948 & 9.61 & 13.4 \\
\hline & 50 & $6.67 \times 10^{-3}$ & 3.76 & 0.8836 & $1.51 \times 10^{-2}$ & 0.724 & 6.93 & 0.9983 & 7.95 & 12.7 \\
\hline & 25 & $1.19 \times 10^{-2}$ & 1.16 & 0.8990 & $7.16 \times 10^{-2}$ & 1.39 & 4.41 & 0.9994 & 4.64 & 8.6 \\
\hline
\end{tabular}

(calculated and experimental data, $q_{\mathrm{e}, \mathrm{calc}}$ and $q_{\mathrm{e}, \mathrm{exp}}$ ) and the deviation $\Delta q(\%)$ for the pseudo-second-order model (Eq. 9).

$\Delta q(\%)=100 \times \sqrt{\frac{\sum_{i=1}^{n}\left(q_{t, \mathrm{exp}}-q_{\mathrm{t}, \mathrm{calc}}\right) / q_{t, \mathrm{exp}}}{n-1}}$

where $n$ represents the number of experimental data, $q_{\mathrm{t}, \mathrm{calc}}$ the metal uptake calculated for the time $t\left(\mathrm{mg} \mathrm{g}^{-1}\right)$ and $q_{\mathrm{t}, \text { exp }}$ the experimental metal uptake at time $t\left(\mathrm{mg} \mathrm{g}^{-1}\right)$.

From data presented in Table 2, it is possible to assume the pseudo-second-order equation rate as the kinetic model that best fits to the experimental results. Similar research works, comparing both chemical reaction models to describe heavy metal biosorption kinetics, establish an identical pattern (Aksu 2001; Benguella and Benaissa 2002; Chojnacka 2005; Lu and Gibb 2008; Li et al. 2009a; Akar et al. 2013).

Both TSG and NTSG presented increasing equilibrium rate constants of pseudo-second-order sorption $\left(k_{2}\right)$ with decreasing $\mathrm{Cr}$ (III) initial concentration. The higher initial sorption rate $(h)$ obtained in dilute solutions explains the shorter sorption times needed to reach equilibrium. Ozer et al. (2004) and Chojnacka (2005), respectively, studying $\mathrm{Cu}$ (II) uptake by Cladophora crispata and $\mathrm{Cr}$ (III) uptake by eggshells explained this behavior by the reduction of the diffusion of metal ions in the boundary layer and the diffusion enhancement in the solid caused by the increasing metal concentration.

Fast kinetics is highly relevant for biosorption applications as allows the use of lower volume bioreactors, contributing to process economy and efficiency. Within the metal concentration range used in this study, both
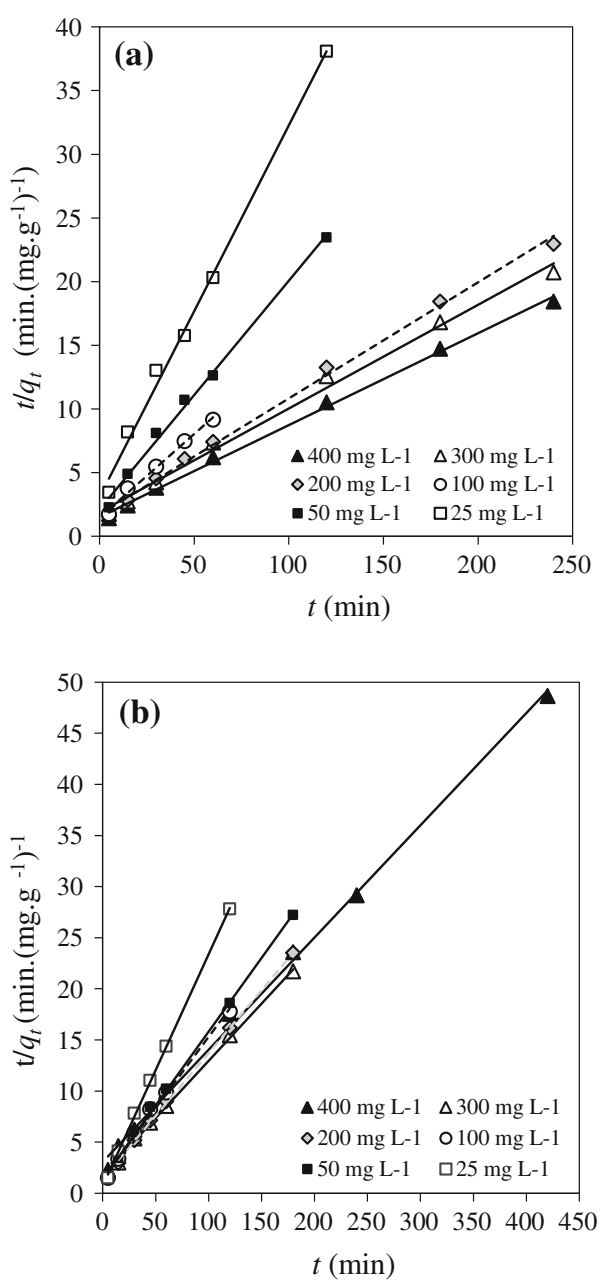

Fig. 3 Pseudo-second-order sorption kinetics of Cr(III) onto brewery spent grains at different initial metal concentrations: a NTSG; b TSG 

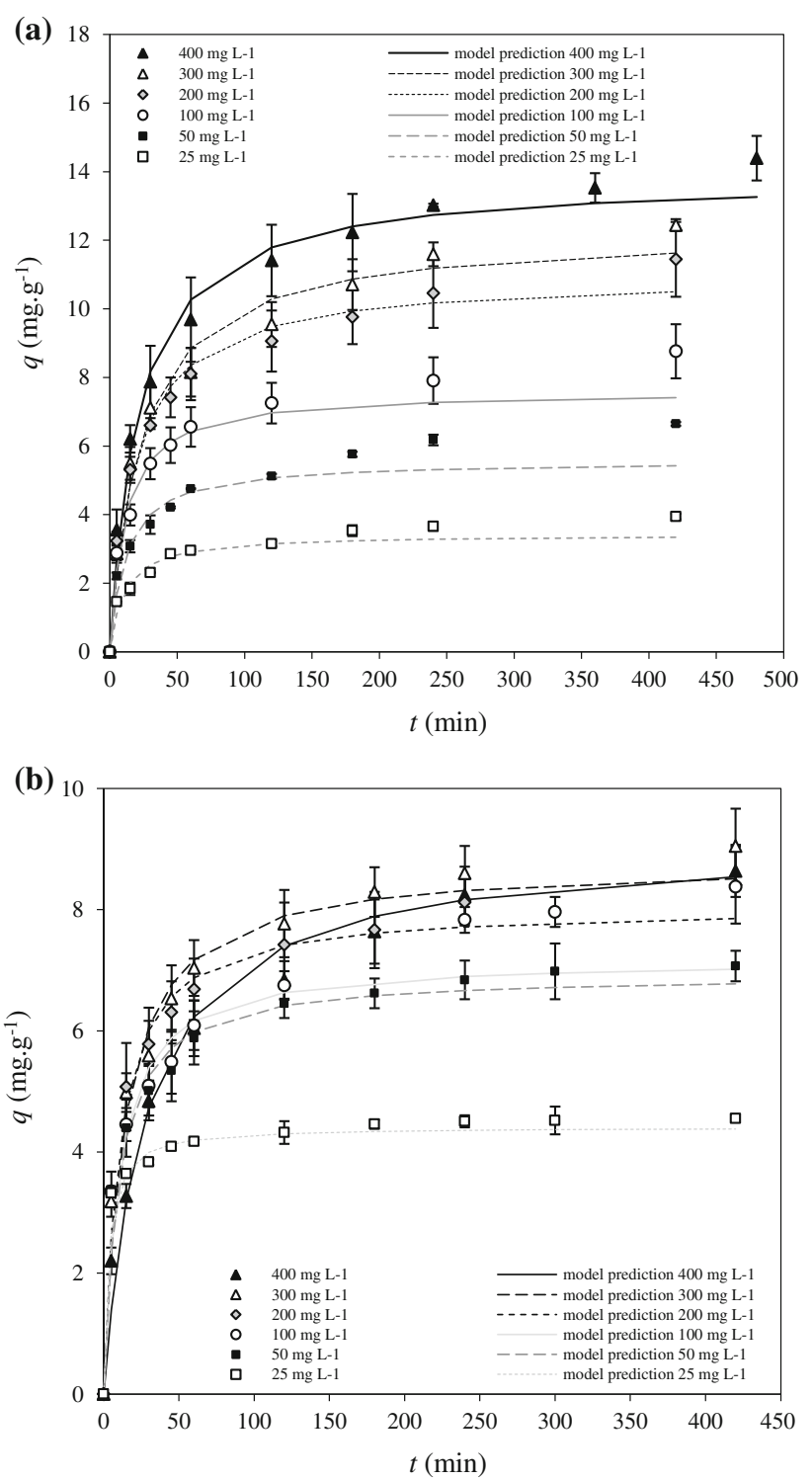

Fig. 4 Comparison of experimental values of $\mathrm{Cr}$ (III) uptake by NTSG (a) and TSG (b) and pseudo-second-order model predictions

biosorbents have similar behavior regarding pseudo-second-order constants $\left(k_{2}\right)$. Plots in Fig. 3 exhibit the pseudosecond-order rate equation linear fitting to the experimental results obtained in the first rapid sorption phase. Figure 4 presents the experimental $\mathrm{Cr}(\mathrm{III})$ uptake data and the uptake values predicted by this kinetic model during the first $8 \mathrm{~h}$. This comparison turns evident the increasing deviation between experimental and predicted $q_{\mathrm{t}}$ values with increasing sorption time.

Despite similar biosorption studies generally determine a unique kinetic model to describe the metal uptake rate, in this study, it is not possible to find a unique kinetic model to fit the whole biosorption data range. The initial sorption phase, best described by the pseudo-second-order kinetic model, indicates that chemisorption is the dominating biosorption mechanism occurring in this period. For longer contact times, intraparticle diffusion assumes an important contribution to the overall $\mathrm{Cr}$ (III) uptake rate. An identical behavior was described when using meranti sawdust for $\mathrm{Cr}(\mathrm{III})$ removal from aqueous solution, with the adsorption kinetics following the pseudo-second-order kinetic model and the rate-controlling step mainly intraparticle diffusion (Rafatullaha et al. 2009).

$\mathrm{Cr}(\mathrm{III})$ sorption equilibrium

Linear forms of Langmuir and Freundlich isotherms (Eqs. 10, 11) were fitted to equilibrium isotherms experimental data.

$\frac{C_{\mathrm{f}}}{q_{\mathrm{e}}}=\frac{1}{q_{\max } b}+\frac{1}{q_{\max }} C_{\mathrm{f}}$

$\ln q=\ln K_{\mathrm{F}}+\frac{1}{N} \ln C_{\mathrm{e}}$

Table 3 summarizes Langmuir and Freundlich models parameters, their correlation coefficients $\left(r^{2}\right)$ determined by the least squares fit to the experimental data, as well as the $\mathrm{Cr}$ (III) uptake for final metal concentration in solution of 10 and $200 \mathrm{mg} \mathrm{L}^{-1}\left(q_{10}\right.$ e $\left.q_{200}\right)$ predicted by Langmuir model. Calculated correlation coefficients are similar in their values, and are higher than 0.99 , except for the Freundlich model concerning NTSG. Therefore, it can be assumed that the Langmuir model fits better to the experimental results over the experimental range.

The model parameters, $b$ and $q_{\max }$, reflecting the sorbent nature may be useful to compare biosorption systems performance and are considered important indicators to compare different sorbents at saturation conditions and to assess the biosorption potential of organic materials, providing useful information to predict biosorption uptake efficiency and to evaluate the necessary amount of biosorbent to treat a wastewater with a known metal concentration (Benguella and Benaissa 2002). Data in Table 3 show that biosorbents in study have similar affinity to $\mathrm{Cr}(\mathrm{III})$, but NTSG has the higher $\mathrm{Cr}$ (III) maximum uptake capacity $\left(q_{\max }=16.7 \mathrm{mg} \mathrm{Cr}(\mathrm{III}) \mathrm{g}^{-1}\right)$.

Farinella et al. (2007) suggested that metal ions binding to lignocellulosic materials occur through carboxyl, amino or phenolic functional groups. The observed decrease in spent grains metal uptake capacity resulting from the alkaline pre-treatment may arise from subsequent chemical or structural changes interfering in quantity and availability of biosorbent-biding sites. These results, contradicting the behavior described by Low et al. (2000) for Cd(II) and $\mathrm{Pb}$ (II) biosorption with brewery spent grains where alkaline pre-treatment increased metal biosorption, could take place from differences between the role of individual functional 
Table 3 Freundlich and Langmuir parameters obtained from the experimental data linear fitting for $\mathrm{Cr}$ (III) biosorption by spent grains

\begin{tabular}{|c|c|c|c|c|c|c|c|c|}
\hline \multirow[t]{2}{*}{ Biosorbent } & \multicolumn{3}{|l|}{ Freundlich model } & \multicolumn{5}{|c|}{ Langmuir model } \\
\hline & $K_{F}\left(\mathrm{mg}^{1-1 / \mathrm{N}} \mathrm{L}^{1 / \mathrm{N}} \mathrm{g}^{-1}\right)$ & $N$ & $r^{2}$ & $q_{\max }\left(\mathrm{mg} \mathrm{g}^{-1}\right)$ & $b\left(\mathrm{~L} \mathrm{~g}^{-1}\right)$ & $r^{2}$ & $q_{10}\left(\mathrm{mg} \mathrm{g}^{-1}\right)$ & $q_{200}\left(\mathrm{mg} \mathrm{g}^{-1}\right)$ \\
\hline NTSG & 4.59 & 4.52 & 0.9758 & 16.68 & 0.0592 & 0.9911 & 6.20 & 15.38 \\
\hline TSG & 5.27 & 6.41 & 0.9944 & 13.64 & 0.0667 & 0.9921 & 5.45 & 12.68 \\
\hline
\end{tabular}

groups involved in binding to different metals. According to Pearson metal classification, $\mathrm{Cr}$ (III) belongs to Class A (strong metals) having the following preference order to functional groups binding ligands: $\mathrm{O}>\mathrm{N}>\mathrm{S}$. Cadmium, classified as a weak metal (Class B), has the opposite preference order, and lead is a transition metal (Mack et al. 2007). It is possible that alkaline treatment effects in spent grains functional groups may benefit Class B and transition metal biosorption while prejudices Class A metal biosorption.

Comparing both biosorbents performance at low and high $\mathrm{Cr}$ (III) concentrations through $q_{10}$ and $q_{200}$ values, NTSG has higher values, respectively, 6.20 and $15.38 \mathrm{mg} \mathrm{g}^{-1}$. Despite the lower $b$ value calculated for TSG, the spent grains with no chemical treatment accumulates more metal at a final concentration of $10 \mathrm{mg} \mathrm{L}^{-1}$, suggesting that the higher affinity to $\mathrm{Cr}$ (III) occurs for even lower concentrations. However, $q_{200}$ values, very close to biosorbent saturation according to experimental isotherms, reflect the expected behavior predicted from $q_{\text {max }}$.

Chemically modified lignocellulosic materials may have enhanced biosorption capacity, but the cost of chemicals and technologies used has to be taken into consideration in order to produce low-cost adsorbents (Miretzky and Cirelli 2010). In that regard, the better performance of NTSG may be assumed as an additional advantage when used to treat wastewaters contaminated with $\mathrm{Cr}$ (III). Furthermore, comparing NTSG maximum uptake capacity for $\mathrm{Cr}$ (III) with other biosorbents, it is possible to consider this lowcost residual biomass as a promising biosorbent: $q_{\max }($ carrot residues $)=45.09 \mathrm{mg} \mathrm{g}^{-1}$ (Nasernejad et al. 2005), $q_{\max }$ (orange wastes) $=74,83 \mathrm{mg} \mathrm{g}^{-1}$ (Marín et al. 2009), $q_{\max }($ sorghum straw $)=6.96 \mathrm{mg} \mathrm{g}^{-1}, \quad q_{\max }$ (oats straw $)=12.97 \mathrm{mg} \mathrm{g}^{-1}, \quad$ and $\quad q_{\max }($ agave bagasse $)=$ $11.44 \mathrm{mg} \mathrm{g}^{-1}$ (Bernardo et al. 2009), $q_{\max }($ L. hexandra Swartz biomass) $=28.64 \mathrm{mg} \mathrm{g}^{-1}$ (Li et al. 2009b) and $q_{\text {max }}($ sunflower stem $)=6.24 \mathrm{mg} \mathrm{g}^{-1}$ (Malik et al., 2005).

Brewery spent grains characterization by FTIR

Metal biosorption onto organic materials involves several accumulation mechanisms including physical adsorption, ion change, coordination, complexation, chelation and precipitation (Wang and Chen 2006), in a combination that differs qualitatively and quantitatively upon biomass type,

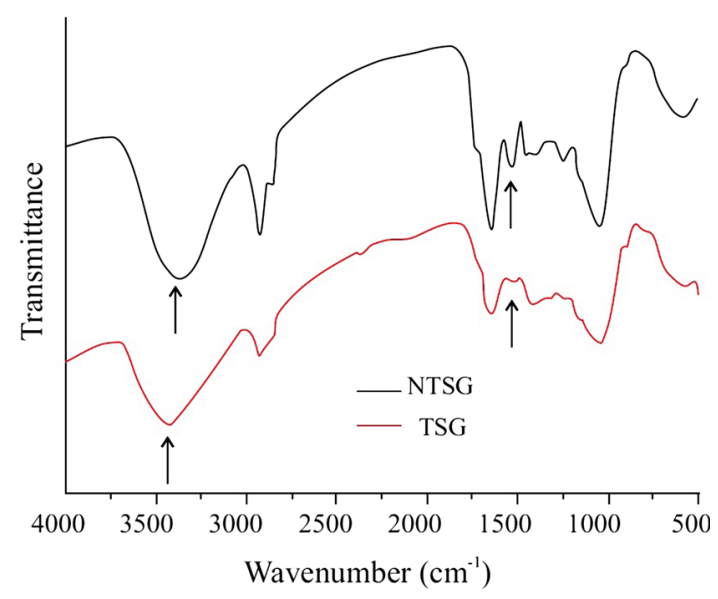

Fig. 5 FTIR spectra obtained for control NTSG and TSG

origin and processing. Therefore, the identification of stoichiometric interactions occurring by ion change or covalent bonding between biosorbent functional groups and metal ions gives important contributions to elucidate the mechanism involved in metal-biosorbent interactions. FTIR spectroscopy is frequently used to detect vibrational frequency changes in biosorbents, offering information about the nature of chemical bonds and biomass superficial functionalities. In fact, infrared spectra analysis is useful to qualitatively approach the nature of biosorbents surface and to identify chemical groups related to heavy metal biosorption properties (Loukidou et al. 2004a), and it is commonly used to obtain structural and bonding information on complex and large molecules.

FTIR spectra (Fig. 5) show the complex nature of spent grains, with the presence of several functional groups with potential to interact with metal ions, namely the carboxyl, hydroxyl, amino and amide groups of hydrocarbons and proteins. Besides molecular complexity, peak assignment shows that alkaline treatment causes changes in spent grains chemical structure. From Fig. 5, it is possible to observe that both spectra have peaks at $1,050 \mathrm{~cm}^{-1}$, corresponding to $\mathrm{C}-\mathrm{O}$ or $\mathrm{C}-\mathrm{N}$ stretching vibrations of primary alcohols or amines, and also peaks at 1,735 and $1,650 \mathrm{~cm}^{-1}$, the first one characteristic of carbonyl group $\mathrm{C}=\mathrm{O}$ stretching vibration in ketones, ethers, aldehydes and carboxylic acids, and the second assigned to the carbonyl group in aromatic rings found in lignin. Peaks at 2,920 and $2,850 \mathrm{~cm}^{-1}$ correspond to $\mathrm{C}-\mathrm{H}$ stretching vibrations in 
aliphatic chains that may belong to cellulose, lignin or hemicellulose. The large band in the 3,600 and 3,200 $\mathrm{cm}^{-1}$ region is assigned to $-\mathrm{H}$ stretching vibration of cellulose, lignin or hemicellulose hydroxyl groups and to the $\mathrm{N}-\mathrm{H}$ stretching in primary amines (Tarley and Arruda 2004).

Arrows drawn in Fig. 5 reveal differences in absorption peaks obtained for biosorbents before contact with chromium solutions, making evidence of changes caused by alkaline treatment. TSG spectrum has the 3,600 and $3,200 \mathrm{~cm}^{-1}$ band larger and shifted to a higher position, indicating changes in alcohols and phenols hydroxyl groups or in $\mathrm{NH}$ bonds. The second change noticed points out the absence of the peak at $1,540 \mathrm{~cm}^{-1}$, where aliphatic nitrogen compounds absorb energy, in a region identified as the protein region. This difference in spent grains composition after alkaline treatment, associated to its diminished metal uptake capacity, suggests that both hydroxyl groups and proteins have an important role in $\mathrm{Cr}$ (III) biosorption onto brewery spent grains.

FTIR spectra obtained for spent grain in contact with chromium solutions with initial concentration of 50 and $200 \mathrm{mg} \mathrm{L}^{-1}$ for $48 \mathrm{~h}$ do not show significant differences from original ones. The absence of the expected differences, resulting from changes in spent grains chemical composition from contact with $\mathrm{Cr}$ (III) solutions, suggests that metal biosorption does not involve covalent bonding to the biomass functional groups. Therefore, $\mathrm{Cr}$ (III) biosorption onto spent grains mainly occurs through electrostatic interactions as other lignocellulosic materials previously studied (Miretzky and Cirelli 2010), with a predominant ionic character in agreement with $\mathrm{Cr}(\mathrm{III})$ classification as Class A metal (strong metal).

$\mathrm{Cr}(\mathrm{III})$ biosorption onto spent grains in expanded bed columns

To assess chromium biosorption onto spent grains performance in expanded bed columns, control assays where prepared with no biomass in the column $(X=0)$. In this condition, Eq. 8 solution is given by:

$C_{\mathrm{e}}=C_{\mathrm{i}}\left(1-e^{-\frac{1}{\theta} t}\right)$

Replacing, in Eq. 12, Langmuir parameters presented in Table 3, the following equations are obtained for NTSG (Eq. 13) and TSG (Eq. 14):

$\begin{aligned} \frac{\mathrm{d} C_{\mathrm{e}}}{\mathrm{d} t} & =\frac{F\left(C_{\mathrm{i}}-C_{\mathrm{e}}\right)}{1.05\left(1+\frac{7044}{\left(C_{\mathrm{e}}+16.9\right)^{2}}\right)} \\ \frac{\mathrm{d} C_{\mathrm{e}}}{\mathrm{d} t} & =\frac{F\left(C_{\mathrm{i}}-C_{\mathrm{e}}\right)}{1.05\left(1+\frac{4090}{\left(C_{\mathrm{e}}+15.0\right)^{2}}\right)}\end{aligned}$

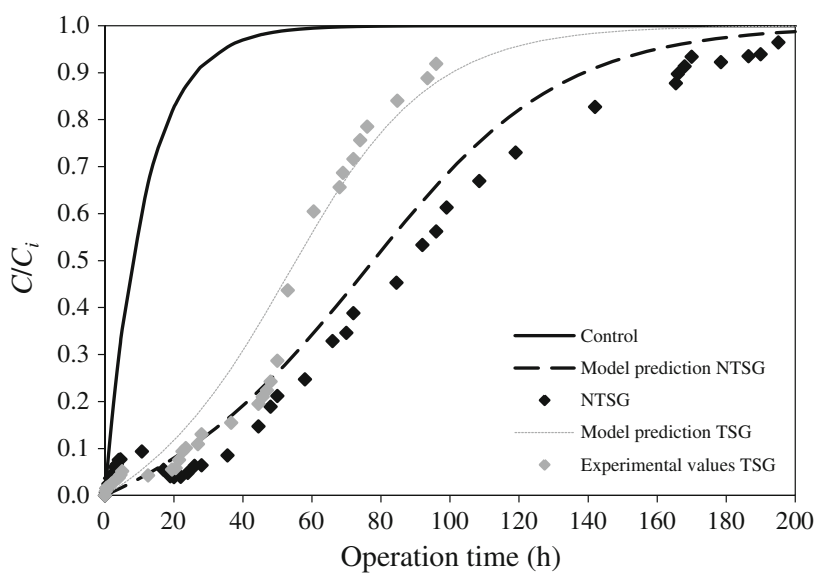

Fig. $6 \mathrm{Cr}(\mathrm{III})$ breakthrough curves $\left(C_{\mathrm{i}}=50 \mathrm{mg} \mathrm{L}^{-1}\right)$ : comparison between experimental assays (control, NTSG and TSG) and model predictions

Solution for these equations was obtained with software MATLAB, considering as initial conditions: $C_{\mathrm{e}}=0$ and $t=0$.

Experimental breakthrough curves are represented in Fig. 6, together with predictions obtained from Eqs. 13 and 14. Comparing with control assay, chromium biosorption onto spent grains results in the reduction of outlet metal concentration from start up through several hours of operation. NTSG exhibits better performance than TSG, making possible to operate nearly $200 \mathrm{~h}$ before reaching column saturation, in consistence with equilibrium data indicating its higher maximum uptake capacity.

Percentage deviations correspond to $59.1 \%$ for NTSG and $57.6 \%$ for TSG, with more significant differences between experimental and calculated values occurring during the first $20 \mathrm{~h}$ of column operation. Breakthrough curves obtained for both biosorbents exhibit the typical " $\mathrm{S}$ " shape. Beyond $20 \mathrm{~h}$ of operation, experimental data follow a trend similar to model prediction, although with lower $C / C_{\mathrm{i}}$ values, revealing that real $\mathrm{Cr}$ (III) uptake overcomes calculated values. Considering hydrodynamics conditions used in continuous experiments, CSTR mass balance equation has valid application. Nevertheless, biosorption performance predictions resulting from models developed do not describe well experimental data considering the operational conditions tested.

Overall Cr(III) uptake corresponds to $15.58 \mathrm{mg} \mathrm{g}^{-1}$ for NTSG and $11.14 \mathrm{mg} \mathrm{g}^{-1}$ for TSG. Experimental breakthrough curves confirm that alkali treatment does not improve spent grains uptake capacity. NTSG accumulated more $\mathrm{Cr}$ (III) than TSG and column operation for longer periods until saturation was reached. In fact, with NTSG, the breakthrough time $\left(C / C_{\mathrm{i}}=0.25\right)$ and the total saturation time $\left(C / C_{\mathrm{i}}=0.99\right)$ occurred after $58 \mathrm{~h}$ and $199 \mathrm{~h}$ of 
operation, corresponding to the accumulation of $390 \mathrm{mg}$ of $\mathrm{Cr}(\mathrm{III}), 43.3 \%$ of the total amount entering the column.

Marín et al. (2009), using orange waste in fixed bed columns (25.5 and $34 \mathrm{~cm}$ height) to remove $\mathrm{Cr}$ (III) from solution, reported the occurrence of the breakthrough time after 17.1 and $25.4 \mathrm{~h}$, and the total saturation time after 48.7 and $57.1 \mathrm{~h}$, respectively with 49.4 and $57.5 \%$ removal of the total amount entering the column. The earlier saturation comparing with similar metal uptake is explained by differences in column hydrodynamics, being the mass transfer zone sharper in fixed bed columns.

\section{Conclusion}

From $\mathrm{Cr}$ (III) kinetic, equilibrium and column studies onto spent grains, it is possible to conclude that metal uptake rate and uptake capacity depend on metal initial concentration and biorsorbent characteristics. Fast kinetics is highly relevant for biosorption applications as allows the use of lower volume bioreactors, contributing to process economy and efficiency. Chemisorption was found to be the dominating mechanism during the first biosorption period. For longer contact times, intraparticle diffusion assumes an important contribution to the overall $\mathrm{Cr}$ (III) uptake rate.

Considering NTSG overall performance, in addition to low processing requirements, the observed physical properties and mechanical resistance along batch and column assays, it can be considered as a promising low-cost biomass to be used in such environmental biotechnology applications, aiming wastewater decontamination and discharge in compliance with legal constraints, simultaneously with the recovery and valorisation of industrial byproducts.

Acknowledgments The authors would like to thank the Portuguese brewing industry UNICER for all the support and FCT (Fundação para a Ciência e a Tecnologia) financial support through the Grant PRAXIS XXI/BD/15945/98.

\section{References}

Acheampong MA, Pereira JPC, Meulepas RJW, Lens PNL (2011) Biosorption of $\mathrm{Cu}$ (II) onto agricultural materials from tropical regions. J Chem Technol Biotechnol 86:1184-1194

Akar T, Celik S, Ari AG, Akar ST (2013) Nickel removal characteristics of an immobilized macro fungus: equilibrium, kinetic and mechanism analysis of the biosorption. J Chem Technol Biotechnol 88:680-689

Aksu Z (2001) Equilibrium and kinetic modeling of cadmium(II) biosorption by $C$. vulgaris in a batch system: effect of temperature. Sep Purif Technol 21:285-294

Aliyu S, Bala M (2011) Brewer's spent grain: a review of its potentials and applications. Afr J Biotechnol 10(3):324-331
Barka N, Abdennouri M, Boussaoud A, Makhfouk ME (2010) Biosorption characteristics of Cadmium(II) onto Scolymus hispanicus L. as low-cost natural biosorbent. Desalination 258:66-71

Benguella B, Benaissa H (2002) Cadmium removal from aqueous solutions by chitin: kinetic and equilibrium studies. Water Res 36:2463-2474

Bernardo GR, Rene RM, Ma. Catalina AD (2009) Chromium(III) uptake by agrowastes biosorbents: chemical characterization, sorption-desorption studies, and mechanism. J Hazard Mater 170:845-854

Branyik T, Vicente A, Oliveira R, Teixeira J (2004) Physicochemical surface properties of brewing yeast influencing their immobilization onto spent grains in a continuous reactor. Biotechnol Bioeng 88:84-93

Carvalheiro F, Esteves MP, Parajo JC, Pereira H, Girio FM (2004) Production of oligosaccharides by autohydrolysis of brewery's spent grain. Bioresour Technol 91:93-100

Chojnacka K (2005) Biosorption of Cr(III) ions by eggshells. J Hazard Mater 121:167-173

Davis TA, Volesky B, Mucci A (2003) A review of the biochemistry of heavy metal biosorption by brown algae. Water Res 37:4311-4330

Donmez G, Kocberber N (2005) Isolation of hexavalent chromium resistant bacteria from industrial saline effluents and their ability of bioaccumulation. Enzyme Microb Technol 36:700-705

Farinella NV, Matos GD, Arruda MAZ (2007) Grape bagasse as a potential biosorbent of metals in effluent treatments. Bioresour Technol 98:1940-1946

Fatima T, Nadeem R, Masood A, Saeed R, Ashraf M (2013) Sorption of lead by chemically modified rice. Int J Environ Sci Technol 10(6): 1255-1264

Ferraz AI, Tavares MT, Teixeira JA (2005) Sorption of Cr(III) from aqueous solutions by spent brewery grain. In: Proceedings of the 9th international chemical engineering conference-CHEMPOR 2005. Coimbra, Portugal

Fonseca B, Maio H, Quintelas C, Teixeira A, Tavares T (2009) Retention of $\mathrm{Cr}(\mathrm{VI})$ and $\mathrm{Pb}(\mathrm{II})$ on a loamy sand soil: kinetics, equilibria and breakthrough. Chem Eng J 152:212-219

Gardea-Torresdey JL, de la Rosa G, Peralta-Videa JR, Montes M, Cruz-Jimenez G, Cano-Aguilera I (2005) Differential uptake and transport of trivalent and hexavalent chromium by tumbleweed (Salsola kali). Arch Environ Contam Toxicol 48(2):225-232

Gulnaz O, Saygideger S, Kusvuran E (2005) Study of $\mathrm{Cu}(\mathrm{II})$ biosorption by dried activated sludge: effect of physico-chemical environment and kinetics study. J Hazard Mater 120:193-200

Ho YS, Mckay G (2004) Sorption of copper(II) from aqueous solution by peat. Water Air Soil Pollut 158:77-97

Ho YS, Ng JCY, Mckay G (2000) Kinetics of pollutant sorption by biosorbents: review. Sep Purif Methods 29:189-232

Li Q, Chai L, Yang Z, Wang Q (2009a) Kinetics and thermodynamics of $\mathrm{Pb}(\mathrm{II})$ adsorption onto modified spent grain from aqueous solutions. Appl Surf Sci 255:4298-4303

Li J, Lin D, Zhang X, Yan Y (2009b) Kinetic Parameters and Mechanisms of the Batch Biosorption of $\mathrm{Cr}(\mathrm{VI})$ and $\mathrm{Cr}(\mathrm{III})$ onto Leersia hexandra Swartz Biomass. J Colloid Interface Sci 333:71-77

Loukidou MX, Zouboulis AI, Karapantsios TD, Matis KA (2004a) Equilibrium and kinetic modeling of chromium(VI) biosorption by Aeromonas caviae. Colloids Surf A 242:93-104

Loukidou MX, Karapantsios TD, Zouboulis AI, Matis KA (2004b) Diffusion kinetic study of chromium(VI) biosorption by Aeromonas caviae. Ind Eng Chem Res 43:1748-1755

Low KS, Lee CK, Liew SC (2000) Sorption of cadmium and lead from aqueous solutions by spent grain. Process Biochem 36:59-64 
Low KS, Lee CK, Low CH (2001) Sorption of chromium (VI) by spent grain under batch conditions. J Appl Polym Sci 82:2128-2134

Lu S, Gibb SW (2008) Copper removal from wastewater using spentgrain as biosorbent. Bioresour Technol 99:1509-1517

Macheiner D, Adamitsch BF, Karner F, Hampel WA (2003) Pretreatment and hydrolysis of brewer's spent grains. Eng Life Sci 3:401-405

Mack C, Wilhelmi B, Duncan JR, Burgess JE (2007) Biosorption of precious metals. Biotechnol Adv 25:264-271

Malik UR, Hasany SM, Subhani MS (2005) Sorptive potential of sunflower stem for $\mathrm{Cr}(\mathrm{III})$ ions from aqueous solutions and its kinetic and thermodynamic profile. Talanta 66:166-173

Marín ABP, Aguilar MI, Meseguer VF, Ortuño JF, Sáez J, Lloréns M (2009) Biosorption of chromium(III) by orange (Citrus cinensis) waste: batch and continuous studies. Chem Eng J 155:199-206

Marín ABP, Aguilar MI, Ortuño JF, Meseguer VF, Sáez J, Lloréns M (2010) Biosorption of $\mathrm{Zn}$ (II) by orange waste in batch and packed-bed systems. J Chem Technol Biotechnol 85:1310-1318

Miretzky P, Cirelli AF (2010) Cr(VI) and Cr(III) removal from aqueous solution by raw and modified lignocellulosic materials: a review. J Hazard Mater 180:1-19

Nasernejad B, Zadeh TE, Pour BB, Bygi ME, Zamani A (2005) Comparison for biosorption modeling of heavy metals $(\mathrm{Cr}(\mathrm{III})$, $\mathrm{Cu}(\mathrm{II}), \mathrm{Zn}(\mathrm{II})$ ) adsorption from wastewater by carrot residues. Process Biochem 40:1319-1322

Ozer A, Ozer D, Ekiz HI (2004) The equilibrium and kinetic modeling of the biosorption of copper(II) ions on Cladophora crispata. Adsorption 10:317-326

Quintelas C, Fonseca B, Silva B, Figueiredo H, Tavares T (2009) Treatment of chromium(VI) solutions in a pilot-scale bioreactor through a biofilm of Arthrobacter viscosus supported on GAC. Bioresour Technol 100:220-226
Rafatullaha M, Sulaimana O, Hashima R, Ahmad A (2009) Adsorption of copper(II), chromium(III), nickel(II) and lead(II) ions from aqueous solutions by meranti sawdust. J Hazard Mater 170:969-977

Reddad Z, Gerente C, Andres Y, Thibault JF, Le Cloirec P (2003) Cadmium and lead adsorption by a natural polysaccharide in MF membrane reactor: experimental analysis and modeling. Water Res 37(16):3983-3991

Sawalha MF, Peralta-Videa JR, Saupe GB, Dokken KM, GardeaTorresdey JL (2007) Using FTIR to corroborate the identity of functional groups involved in the binding of $\mathrm{Cd}$ and $\mathrm{Cr}$ to saltbush (Atriplex canescens) biomass. Chemosphere 66(8):1424-1430

Tarley CRT, Arruda MAZ (2004) Biosorption of heavy metals using rice milling by-products. Characterisation and application for removal of metals from aqueous effluents. Chemosphere 54:987-995

Veglio F, Beolchini F, Barba D (2000) Experimental study and simulation on the biosorption of copper(II) in membrane reactors: a preliminary study. Ind Eng Chem Res 39(7): $2480-2484$

Volesky B (ed) (2003) Equilibrium biosorption performance. Sorption and biosorption. BV Sorbex, Inc., Montreal, pp 103-116

Wang J, Chen C (2006) Biosorption of heavy metals by Saccharomyces cerevisiae: a review. Biotechnol Adv 24:427-451

Weber WJ, Morris JC (1962) Advances in water pollution research: removal of biologically resistant pollutants from waste waters by adsorption. In: Proceedings of international conference on water pollution symposium, vol 2. Pergamon Press, Oxford, pp 231-266 